\title{
An Integrated Sustainability Assessment Tool Framework
}

\author{
Sherif Mahmoud, Tarek Zayed \\ Concordia University, Montreal, Canada \\ she_mahm@encs.concordia.ca; tarek.zayed@concordia.ca
}

\begin{abstract}
Nowadays, the building industry has many harmful impacts on the environment; the society; and the economy. It possesses a huge share in energy consumption; material and non-renewable resources depletion and profoundly increases the global warming. Accordingly, governments and private sectors are recently concerned about controlling the undesirable consequences accompanying the construction of new buildings and the renovation of existing ones through different procedures and strategies. These practices are the primary concern of the sustainable buildings. The literature review reveals that there are many sustainability rating systems developed in the last few decades. However, each of them has its assessment attributes based on its local context. Besides, none of the rating systems propose a guide for the decision makers to select the best affordable rehabilitation alternatives which can upgrade the sustainability of their buildings. Accordingly, the primary target of this research is to establish an integrated sustainable rating and decision-making tool for sustainable existing buildings. Besides, the developed rating tool adapts according to the dynamic weighting scheme, which varies based on the importance of each of the assessment attributes taking into account the local context of each building. This study introduces a framework illustrating the different procedures and models established and integrated into the developed sustainability assessment tool. Moreover, the study highlights the limitations and the advantages of the proposed integrated assessment tool and how it is superior to many of the existing rating systems.
\end{abstract}

Keywords: Sustainable Rating Systems, BREEAM, LEED, CASBEE, Sustainability Assessment Models

\section{Introduction}

Buildings account for $51 \%$ of global electricity consumption, $40 \%$ of global resources depletion, $32 \%$ of world energy consumption, $25 \%$ of the global water use, and $19 \%$ of energy-related $\mathrm{CO}_{2}$ emissions [2, 1]. The emissions of the greenhouse gasses (GHG) are deemed to be the direct harmful impact of buildings on the environment. The carbon gas and non-carbon gas emissions are the main two types of GHG. The carbon gas emissions arise from the burning of fossil fuels to produce energy that operates the buildings. Non-carbon gas emissions such as halocarbons resulted from consuming various construction materials such as paints, adhesives refrigerants, insulation materials, firefighting materials. etc. [3]. In this context, going towards sustainable buildings will help in lessening GHG emissions and controlling other harmful effects. Sustainable buildings adopt a diverse of mitigating technologies and procedures such as applying efficient lighting and daylight, utilizing energy star rated electrical appliances, using energy efficient HVAC systems, employing adequate insulation, using environmentally friendly refrigerants, integrating renewable sources of energy in buildings, etc. Thus, applying these practices can reduce air pollution, improve health and quality of life for the buildings' users, increase productivity, improving social welfare, and improve energy efficiency $[4,3]$.

Moreover, indigenous variations can significantly change the sustainability performance of the buildings. These changes can be addressed in 1) environmental differences which are climate change (i.e. temperature, wind speed, rainfall frequency, etc.), geographic location, and carbon footprint. 2) social discrepancies which can be referred as culture and tradition differences, working hours, and vacations that affect the building energy use profile; and 3) economic aspects such as the building operation and maintenance fees, the inflation rate, the currency value, the interest rate, availability of adequate budgets...etc. All of these aspects differ in their degree of importance based on the building location. Accordingly, sustainability rating systems should embrace the updating dynamism of the importance of the sustainability assessment attributes while preserving the key evaluation criteria to maintain consistency.

Furthermore, one of the serious challenges that confronting building owners, contractors, and decision makers is the budget limitation when upgrading a traditional building to a sustainable one, or when improving the sustainability performance of sustainable one. In other words, not all the sustainable rehabilitation solutions are affordable. 
Consequently, the challenge is to develop a rating system that is capable of distinguishing the best improvement alternatives which can enhance the sustainability performance of buildings with the available budget.

\section{Background}

Recently, there are many sustainability rating systems have been established around the world. Each of which has its assessment criteria according to its point of view and based on the local context of its country of origin. Additionally, each rating system has its evaluation model. These models may be as simple as a direct aggregation of the achieved points or credits such as LEED, or it can be constant weight-based categories' assessment model such as BREEAM. The following sub-sections will provide a brief overview on some of these existing sustainability rating systems.

\subsection{Existing Rating Systems}

BREEAM (Building Research Establishment's Environmental Assessment Method) rating system was developed in the United Kingdom in 1990. It comprises nine assessment criteria which are management, health and wellbeing, energy, transportation, water, material, land use, and ecology and pollution. It adopts five ranking grades that are unclassified, pass, good, very good, and excellent [5].

LEED (Leadership in Energy and Environmental Design) was established in the USA in 1998. There are many versions of LEED utilized to assess the diverse of buildings' types and scales, for example, new construction, existing buildings, commercial interiors, cores and shell, homes, and neighborhood development. It includes six categories which are sustainable sites, water efficiency, energy and atmosphere, materials and resources, indoor environment quality (IEQ), and innovation and design processes [6].

CASBEE (Comprehensive Assessment System for Building Environmental Efficiency) started in Japan in 2001. CASBEE main frame consists of two main groups: building environmental quality (Q) which comprises indoor environmental quality, quality of services, and outdoor environment on the site; while the second group is building environmental load reduction (LR) that embraces energy, resources and material, and the off-site environment. This rating system awards the final grade according to Building and Environment Efficiency ratio (BEE) [7].

BEAM (Building Environmental Assessment Method) is a voluntary assessment tool for green buildings in Hong Kong. It was founded in 1996 based on BREEAM. This rating is being used to enhance the quality of buildings, reduce environmental impacts of buildings through their lifecycle, and evaluates their facility management practices. This tool tackles seven aspects such as site, management, water use, energy, material and waste, indoor environment quality, and innovations. It has four ratings which are bronze, silver, gold, and excellent for overall evaluated percentages of $40 \%, 55 \%$, $65 \%, 70 \%$ and more respectively $[8,9]$.

Malaysian Institute of Architects first introduced the Green Building Index in 2009. It is utilized on a local scale to assess the performance of the green buildings. It covers six assessment criteria which are energy efficiency, indoor environmental quality; sustainable sites planning and management, material and resources, water efficiency, and innovation. It utilizes four classifications to express sustainability such as: certified from (50\%) to (65\%); silver from $(66 \%)$ to $(75 \%)$; gold from $(76 \%)$ to $(85 \%)$; and platinum from $(86 \%)$ to $(100 \%)[10,11]$.

The BCA green mark was launched in 2005 to promote sustainability in the built environment and increase the awareness of developers, designers, and builders when they start their design and during construction. It embraces five assessment areas which are energy efficiency, water efficiency, environmental protection, indoor environmental quality, and other green features and innovations. It uses four rating benchmarks scheme wich are certified, gold, gold-plus, platinum. These ratings express values from (50\%) to less than (75\%), from (75\%) to less than $(85 \%)$, from (85\%) to $(90 \%)$, and from (90) and more respectively $[12,13]$.

The Green Building Council in Indonesia introduced Greenship rating system for new construction in 2010, and in 2011 it launched a new rating system for existing buildings. It assesses six areas which are appropriate site development, energy efficiency, and conservation, water conservation, material resources and recycle, indoor health and comfort, and building environment management. It comprises four ratings: bronze; silver; gold; and platinum for reaching percentages of $(35 \%),(46 \%),(57 \%)$, and $(73 \%)$ respectively $[14,15]$.

BOMA BESt is a voluntary program designed to provide building owners and builders with a framework for assessing the environmental performance and management of the existing building. It was developed in 2005 in Canada. BOMA stands for Building Owners and Management Association, and BESt stands for Building Environmental Standard. It tackles six assessment aspects which are energy, water, waste and site, emissions and effluents, indoor environment, and 
environmental management system. It has five levels of certification: certified, bronze, silver, gold, platinum. These certification levels can be achieved by reaching 59\% as a minimum; 60-69\%; 70-79\%; 80-89\%; and 90-100\% respectively $[16,17,18]$.

\subsection{Limitations of Existing Rating Tools}

Although there are many rating systems, however, there are some drawbacks which hinder these rating systems to express the actual sustainability performance of buildings when applied worldwide. One of these drawbacks is the lack of a unified identification of sustainability assessment attributes, which can be considered as the principal global aspects of sustainability assessment [19]. Moreover, most of the sustainability rating tools are proved to be inefficient when they are implemented internationally. This deficiency is attributed to the lack of an effective weight implementation in their assessment models; this weight reflects the importance of the sustainability attributes which distinguish countries, regions, or projects from one to another. Furthermore, sustainability rating of buildings is a measure of three major aspects: economy, environment, and society, unfortunately, many rating systems overlooked the financial aspect in the sustainability evaluation. The financial assessment must account for life-cycle costing rather than the capital cost evaluation. Many solutions can be initially affordable but had been proven to be uneconomic through their life cycle when subjected to the time value of money and the recurring costs. Additionally, the majority of the rating systems are confined to the current sustainability evaluation, which they cannot be utilized for future planning. These rating systems do not include a rehabilitation model to provide the decision-makers with alternatives to upgrade the sustainability performance of their buildings within the available budgets.

\section{Integrated Sustainability Assessment Tool Framework}

The proposed sustainability assessment tool is an integration of a group of software and developed models as shown in Fig. 1. The main aim of this integrated process is to provide the building owners and decision makers with two tier sustainability rating tool. This evaluation tool capable of providing a comprehensive view when concerning the current sustainability of buildings. While the second stage is introducing a set of procedures that can improve the sustainability performance of the building within available budget. This step can be implemented when considering the future planning concerning the rehabilitation of buildings. The whole process comprises three main phases which will be explained in details in the following sub-sections.

\subsection{Data Input and Initial Processing Phase}

This phase starts with data collection, which can be divided into three main groups of data. The first group is the building data that includes the drawings of each floor of the building illustrating the spatial dimensions, the size of openings, and the types of finishing materials. The second group is the weights of each of the assessment attributes (i.e. the criteria and the factors). These weights indicate the importance of each of the evaluation criteria based on the local context of the building. The third group is all the data required for the assessment of the seven criteria and their related twenty-four factors as illustrated in Fig. 2.

The BIM physical model is developed by utilizing the building data such as the CAD drawings, the type of exterior walls, type of curtain wall glazing, the floor height, the building orientation, the types of the interior partitions, type of floor and ceiling layers. Afterward, the BIM model is exported to the energy simulation software which is the Integrated Environmental Solutions Software (IES). Another group of data is required to perform the simulation which includes the operation schedule of the building, the main holidays of the country, the type of HVAC system, lighting fixture type and intensity, and the total energy load of the other appliances installed in the building. There are several outputs of the energy simulation process which are the total energy consumption in yearly or monthly basis, the total electricity and natural gas energy consumption, the peak power consumption, etc. These outputs are used in the assessment of the energy category 




Fig. 1: Integrated sustainability assessment tool framework.

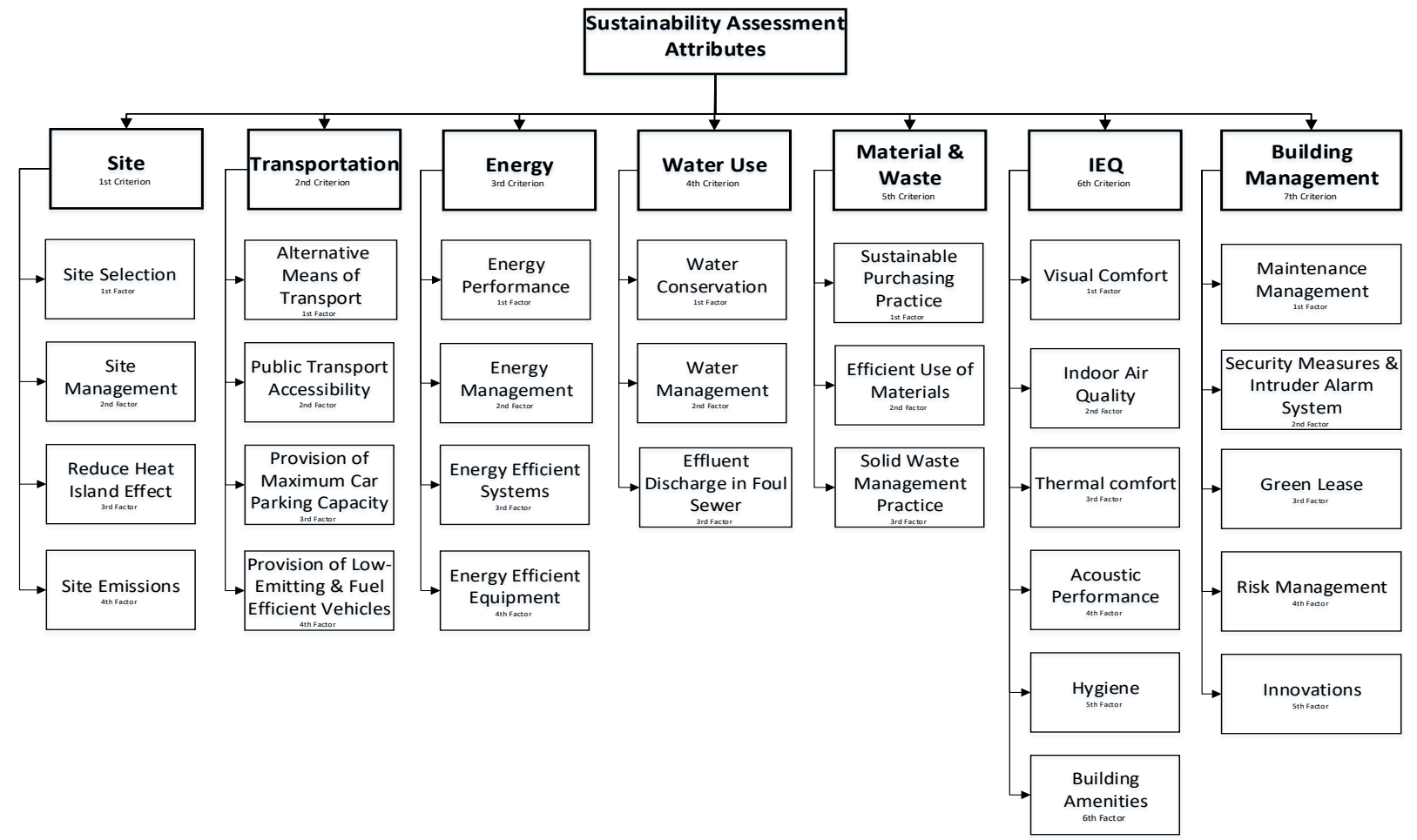

Fig. 2: Sustainability assessment attributes (criteria and factors). 
All the sets of information are gathered and piled in calculation spreadsheets. The first set is the primary data collected from the first phase (the building related data). The second one is the data from Revit model such as the number of floors, the area of exterior glazing, the area of each floor, the types of finishing materials. The third set of data is the output from the energy simulation model which includes the total annual energy consumption, the total annual electricity and gas consumption, the total carbon dioxide equivalent emissions, the peak energy demand. The last source of data is the output from a developed Fuzzy-based model which represents the weight of each criterion and factor.

\subsection{Sustainability Assessment Model Phase}

In this phase, the sustainability assessment model is applied to assess the current sustainability performance of the building based on the previously collected data and the prepared calculation spreadsheets. The evaluation process starts with assigning the weights calculated from the fuzzy-based model to its corresponding criterion and factor. The assessment attributes hierarchy is divided into criteria, factors, and subfactors. The assessment process starts with the evaluation of the factor score which is the summation of all points achieved in the related subfactors as shown in Eq. (1). Then, the factor index is calculated which is the product of a corresponding weight of a factor and its score as illustrated in Eq.(2). Further, the criteria index is the aggregation of the indices of its related factors. Finally, the building sustainability index (BSI) is the summation of all the factors' indices or all the criteria's indices as shown in Eq.(3). The building sustainability assessment (BSA) is the percentage between the BSI and the maximum BSI as shown in Eq.(4).

The sustainability assessment model has two main outputs: 1) the achieved sustainability percentages of each criterion which is the ratio between the criterion index and the criterion maximum index as shown in Eq. (5), and Fig. 3; 2) the final BSA ranking in which the model proposed six sustainability ranks: Fail, Pass, good, very good, excellent, and outstanding for the following BSA values, under 50, 50-<60, 60-<70, 70-<80, 80-<90, and 90-100 as shown in Fig. 4. This scale is determined according to a survey conducted through the research based on a questionnaires and the expert opinions.

$$
\begin{gathered}
S C f_{j}=\sum_{i=1}^{l} S C_{s u b f_{i}} \\
I f_{j}=S C f_{j} \times W_{j} \\
B S I=\sum_{j=1}^{m} I f_{j} \\
B S A=\frac{B S I}{B S I_{\max }} \times 100 \\
P C_{k}=\frac{\sum_{j=1}^{m} I f_{j}}{\sum_{j=1}^{m}\left(I f_{j}\right)_{\max }}
\end{gathered}
$$

Where:

$$
\begin{aligned}
\mathrm{SC}_{\mathrm{j}} & =\text { The score of the } \mathrm{j}^{\text {th }} \text { factor; } \\
\mathrm{SC}_{\text {subf }_{\mathrm{i}}} & =\text { The score of the } \mathrm{i}^{\text {th }} \text { sub-factor; } \\
\mathrm{If}_{j} & =\text { The index of } \mathrm{j}^{\text {th }} \text { factor; and } \\
P c_{k} & =\text { The sustainability percentage of the } \mathrm{k}^{\text {th }} \text { criterion. }
\end{aligned}
$$




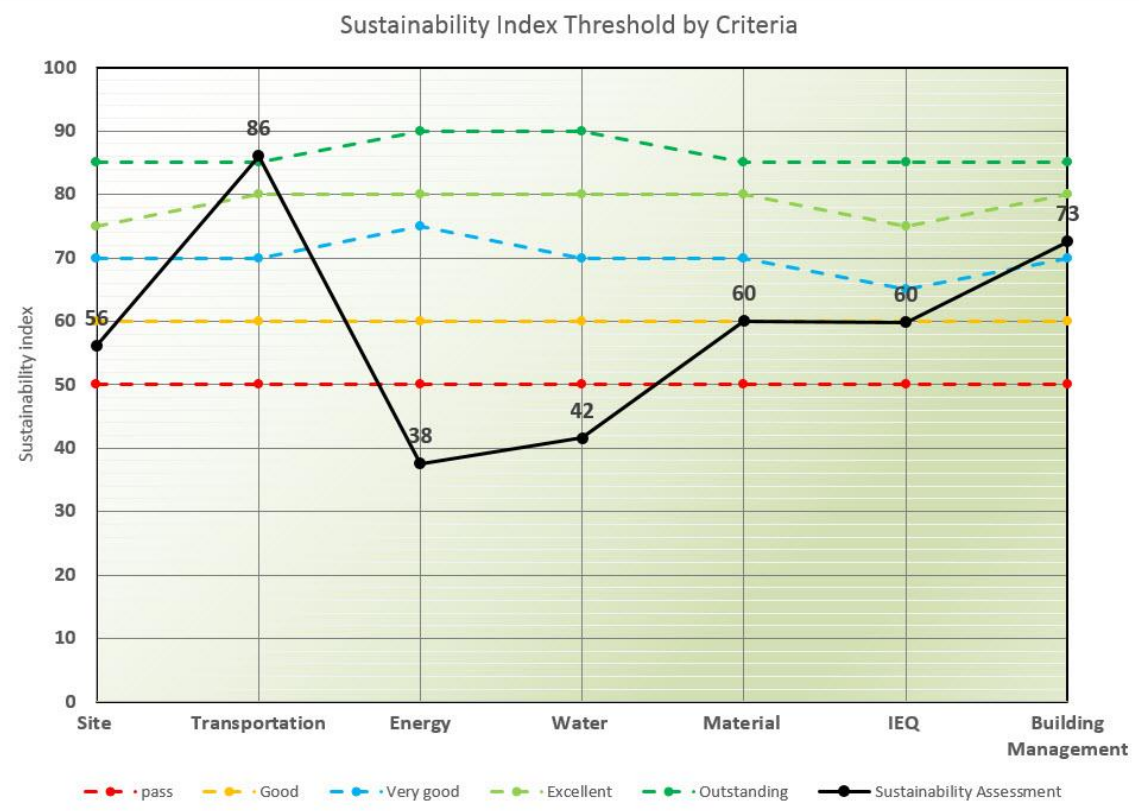

Fig. 3: The Sustainability percentage of criteria.

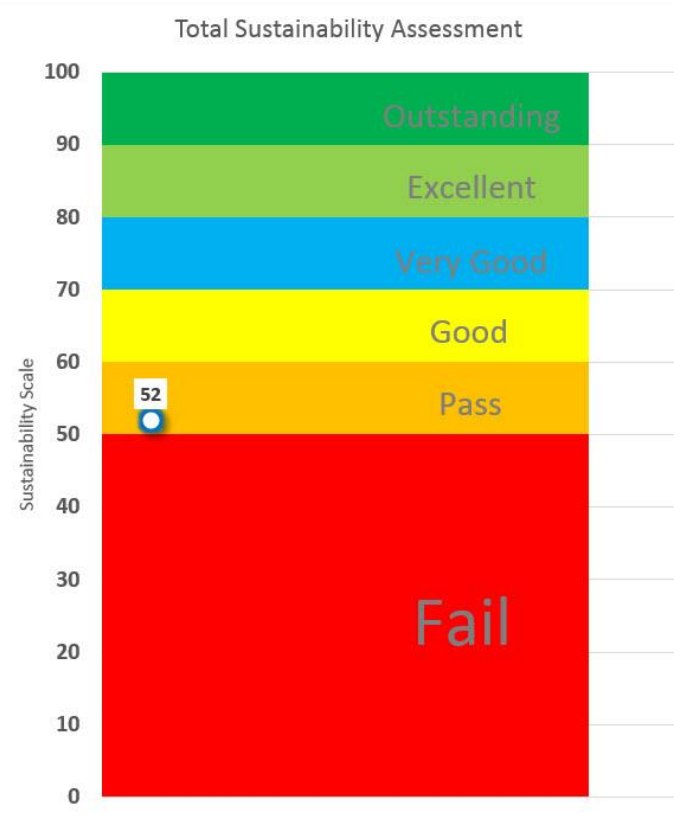

Fig. 4: The plotting of the sustainability assessment output on the proposed scale.

\subsection{Sustainability Based-Rehabilitation Model Development Phase}

The sustainability based rehabilitation model aims to provide the decision makers with the near optimal rehabilitation alternatives required to upgrade the sustainability rating of their building within the available budget. This model an optimization algorithm based on the artificial immune system optimization algorithm (AIS). The number of the decision variables utilized in this model to improve the sustainability of the building are 135 decision variable. This number represents the number of the subfactors used in the assessment model. Each decision variable comprises some alternatives ranging from two to twenty-nine. The input data consists of four main groups as follows: 1) score of each rehabilitation alternative based on the performance constraints fulfillment of each subfactor; 2) cost of each rehabilitation alternative as shown in Fig. 5; 3) the available budget constraint; and 4) the range of the required sustainability index constraint. The 
output of this model is some sets of optimal rehabilitation alternatives needed to upgrade the sustainability of the building within available budget as shown in Fig. 6.

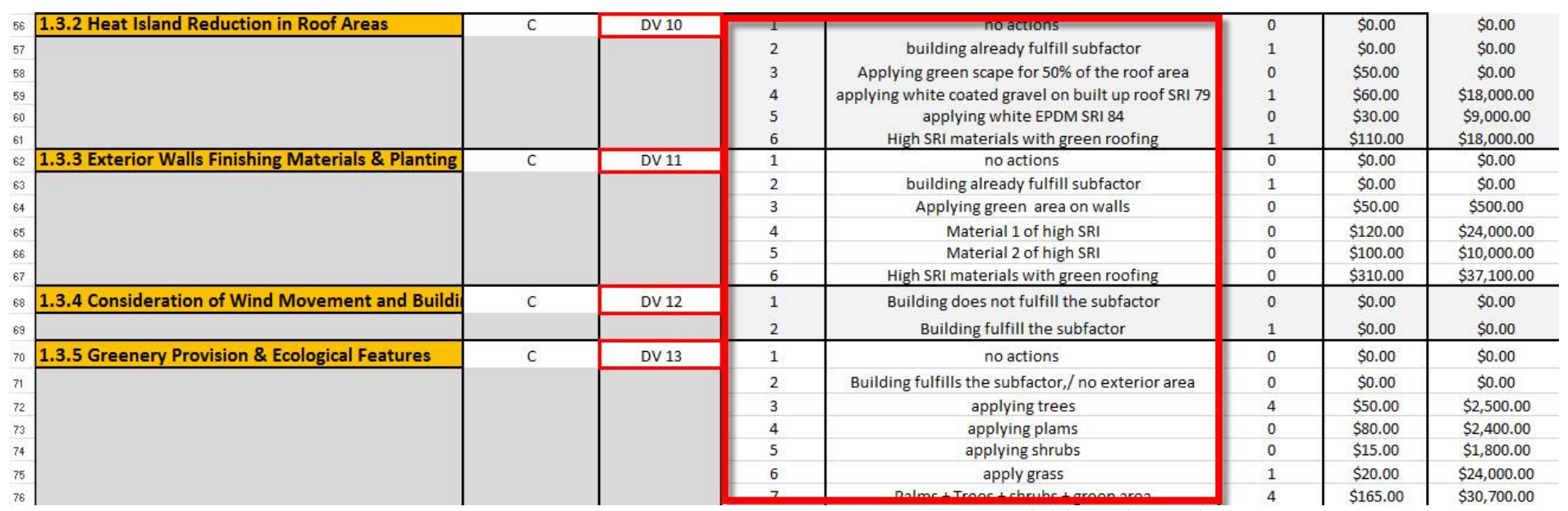

Fig. 5: The sustainability score and cost of decision variables' alternatives.

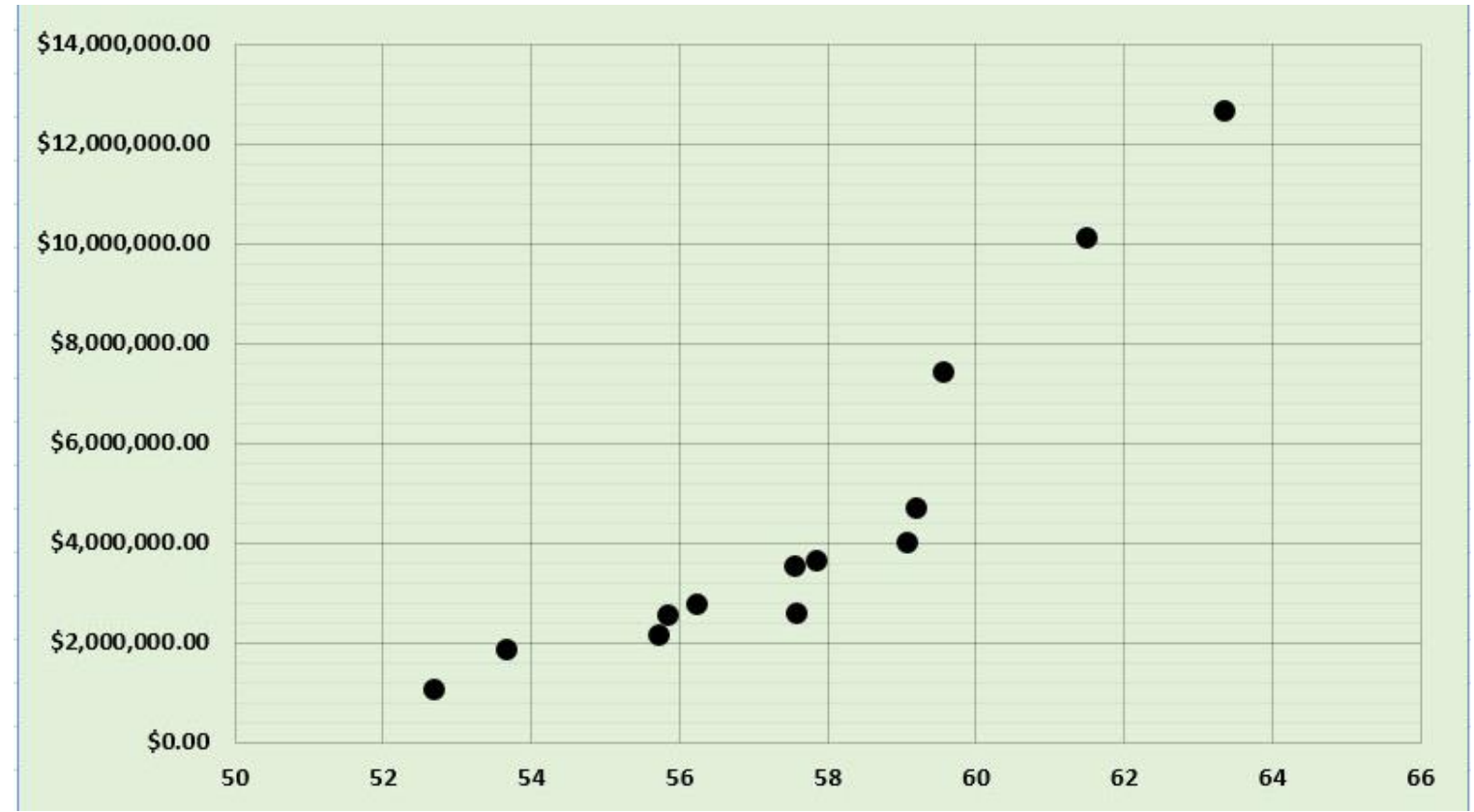

Fig. 6: The max BSA and the min LCC of the near optimum set of alternatives.

\section{Conclusion}

The developed integrated sustainability assessment tool aims to overcome the limitation of the existing rating systems which are previously discussed and to assess sustainability efficiently according to the variable characteristics of the different regions or projects introducing dynamic weighting in the assessment process. The model uses relativity in its assessment rather than absolute assessment. In other words, the developed sustainability assessment model depends on the ratio between the achieved points to the maximum available points rather than a direct aggregation of the gained points. Also, it integrates weight of factors and criteria in the assessment to reflect the local variations and the indigenous character of each building and project. However, one of the limitations of the developed integrated tool is that the existence of some degree of subjectivity in the weight determination, as it was dependent on the responses of the experts through questionnaires. Moreover, the integrated tool can be utilized for future planning, as it is capable of providing the decision makers with a group of alternatives that can improve the sustainability of their buildings within certain budgets. 


\section{References}

[1] UNEP, "United Nations Environment Programme," (2016, August 10), [Online]. Available: http://www.unep.org/sbci/AboutSBCI/Background.asp

[2] IPCC, "Climate Change 2014: Mitigation of Climate Change. The contribution of Working Group III to the Fifth Assessment Report of Intergovernmental Panel on Climate Change," Cambridge University Press, Cambridge, United Kingdom and New York, 2014.

[3] UNEP, "Buildings and Climate Change: Summary for Decision Makers," United Nations Environmental Programme, Paris, 2009.

[4] IPCC, "Climate Change Mitigation. The contribution of Working Group III to the Fourth Assessment Report of the Intergovernmental," Cambridge University Press, Cambridge, 2007.

[5] BRE, BREEAM In-Use International: Technical Manual, SD221 - 1.0:2015 ed., Hertfordshire: BRE Global Ltd, 2015.

[6] USGBC, LEED Reference Guide foGreen Building Operations and Maintenance for the Operations and Maintenance of Commercial and Institutional Buildings, 2009 Edition, Washington, DC: U.S. Green Building Council, 2009.

[7] JaGBC, CASBEE for New Construction: Comprehensive Assessment System for Building Environmental Efficiency Technical Manual, 2008 ed., Japan: Institute for Building Environment and Energy Conservation (IBEC), 2008.

[8] HK GBC, BEAM Plus: Existing Buildings, version 1.2 ed., Hong Kong: BEAM Society Limited., 2012.

[9] Kelcroft, "Kelcroft," (2016, April 4), [Online]. Available: http://www.kelcroftasia.com/services/beamplus.html\#.Vy2g1IQrJhF

[10] GBI, GBI Assessment Criteria for Non-Residential Existing Buildings, First edition, version 1.1 ed., Kuala Lumpur: Green Building Index, 2011.

[11] GREENBUILDINGINDEX SDN BHD, "Green Building Index," (2016, May 7), [Online]. Available: http://new.greenbuildingindex.org/how/classification

[12] BCA, BCA Green Mark for Existing Non-Residential Buildings, Version 3.0, Singapore: Building and Construction Authority, 2012.

[13] Singapore Government, "Building and Construction Authority," 2016, [Online]. Available: https://bca.gov.sg/GreenMark/green_mark_criteria.html

[14] GBC Indonesia, Greenship Existing Building for Existing Building: Benchmark Summary, Version 1.0, Indonesia: Green Building Council Indonesia, 2011.

[15] GBC Indonesia, Greenship New Buildings: Summary of Criteria and Bench Mark, Version 1.1 ed., Jakarta: Green Building Council Indonesia, 2012.

[16] BOMA Canada, BOMA BESt Assessment Overview: BOMA Building Environmental Standards (Office Module), Canada: BOMA Canada, 2013.

[17] J. Smiciklas, BOMA BEST Portfolio Program: Continous Certification Program for: Offices, Enclosed Shopping Centers, Open Air Retail, Light Industrial, Multi-Unit Residential Buildings, Toronto: BOMA Canada, 2016.

[18] The Building Owners and Managers Association of Canada Inc., "BOMA BEST Building Environmental Standard," (2016, May 7), [Online]. Available: http://www.bomabest.com/about-boma-best/

[19] G. Ding, "Sustainable Construction: The Role of Environmental Assessment Tools," Journal of Environmental Management, vol. 86, pp. 451-464, 2008. 